\title{
C9orf72-related disorders: expanding the clinical and genetic spectrum of neurodegenerative diseases
}

\author{
Distúrbios relacionados ao C9orf72: expandindo o espectro clínico e genético das doenças \\ neurodegenerativas
}

Paulo Victor Sgobbi de Souza, Wladimir Bocca Vieira de Rezende Pinto, Acary Souza Bulle Oliveira

\begin{abstract}
Neurodegenerative diseases represent a heterogeneous group of neurological conditions primarily involving dementia, motor neuron disease and movement disorders. They are mostly related to different pathophysiological processes, notably in family forms in which the clinical and genetic heterogeneity are lush. In the last decade, much knowledge has been acumulated about the genetics of neurodegenerative diseases, making it essential in cases of motor neuron disease and frontotemporal dementia the repeat expansions of C9orf72 gene. This review analyzes the main clinical, radiological and genetic aspects of the phenotypes related to the hexanucleotide repeat expansions (GGGGCC) of C9orf72 gene. Future studies will aim to further characterize the neuropsychological, imaging and pathological aspects of the extra-motor features of motor neuron disease, and will help to provide a new classification system that is both clinically and biologically relevant.
\end{abstract}

Keywords: neurodegenerative diseases, motor neuron disease, frontotemporal dementia, parkinsonism, C9orf72.

\section{RESUMO}

As doenças neurodegenerativas representam um grupo heterogêneo de condições neurológicas envolvendo fundamentalmente síndromes demenciais, doenças do neurônio motor e distúrbios de movimento. Relacionam-se, em sua maioria, a processos fisiopatológicos distintos, destacadamente nas formas familiares em que a heterogeneidade clínica e genética são exuberantes. Na última década, muito conhecimento se acumulou a respeito da genética das doenças neurodegenerativas, tornando-se bastante importante nos casos de doenças do neurônio motor e de demência frontotemporal as expansões de repetições do gene C9orf72. Esta revisão aborda os principais aspectos clínicos, radiológicos e genéticos relativos aos fenótipos relacionados à expansão de repetição do hexanucleotídeo (GGGGCC) no gene C9orf72. Estudos futuros vão objetivar a caracterização dos aspectos neuropsicológicos, de imagem e patológicos dos achados extra-motores da doença do neurônio motor e ajudarão a fornecer um novo sistema de classificação relevante em termos clínicos e biológicos.

Palavras-chave: doenças neurodegenerativas, doença do neurônio motor, demência frontotemporal, parkinsonismo, C9orf72.

Neurodegenerative diseases represent a heterogeneous group of neurological conditions primarily involving dementia, motor neuron disease and movement disorders. A wide group of different pathophysiological and genetic mechanisms are involved in this group. Knowledge regarding the genetic basis of sporadic and familial cases of neurodegenerative disorders is growing and new evidences about the involvement of previously unknown genes are the rule. This is particularly true in cases with complex motor and cognitive phenotypes.

Motor neuron disease comprises four main different clinical forms of upper and lower motor neuron involvement: primary lateral sclerosis; progressive muscular atrophy; progressive bulbar palsy; and amyotrophic lateral sclerosis (ALS). ALS represents the most common form of progressive neurodegenerative motor neuron disease with upper and lower motoneuron compromise, clinically defined through specific clinical and electroneuromyographic diagnostic criteria, the so-called El Escorial revised criteria and the Awaji-shima electrodiagnostic criteria. However, ALS is more than a pure motor neuron disease. It is a heterogeneous syndrome with clinical, pathological and genetic overlap with frontotemporal dementia ${ }^{1}$.

Universidade Federal de São Paulo, Departamento de Neurologia e Neurocirurgia, Divisão de Doenças Neuromusculares, Sao Paulo SP, Brazil.

Correspondence: Wladimir Bocca Vieira de Rezende Pinto; Rua Pedro de Toleto, 650; 04023-900 São Paulo SP, Brasil; E-mail: wladimirbvrpinto@gmail.com Conflict of interest: There is no conflict of interest to declare.

Received 03 October 2014; Received in final form 05 November 2014; Accepted 25 November 2014. 
Frontotemporal lobar degeneration (or simply frontotemporal dementia) (FTD) represents one of the most common and wide studied neurodegenerative group of cognitive and behavioural conditions, generally giving rise to an earlyonset dementia with behavioural disturbances involving three particular clinical syndromes ${ }^{2,3,4}$ : the so-called behavioural variant frontotemporal dementia (bvFTD), semantic variant of primary progressive aphasia (svPPA) and nonfluent/agrammatic variant of primary progressive aphasia (nflvPPA). A logopenic variant of primary progressive aphasia has also been considered.

Despite its major presentation as a cognitive and behavioral disturbance, in some cases of FTD, motor involvement is prominent. Since 2006, there is growing evidence about the participation of a major gene locus involved in FTD and ALS phenotypes located on chromosome 9p (the previously known chromosome 9p-linked FTD with ALS) ${ }^{4,5}$, which subsequently in 2011 proved to represent an hexanucleotide repeat expansion in the non-coding region of $C 9$ orf 72 gene $^{6,7}$.

ALS can be viewed as resulting from a complex convergence of genetic susceptibility, age-related loss of cellular homeostasis, and possible environment influences. The rapid increase in recent years of the number of genes in which mutations have been associated with ALS has led to in vitro and in vivo models that have generated a wealth of data indicating disruption of specific biochemical pathways and subcellular compartments, including protein misfolding, mRNA splicing, axonal transport, oxidative stress, proteasome and mitochondrial dysfunctions (Figure 1). Since the identification of the C9orf72 gene, the mechanisms of the interaction between cellular degeneration and system level degeneration have been better elucidated, providing a roadmap for developing novel treatments based on specific targeting of gene mutations. The aim of this review is to focus in the main information regarding genetic, pathophysiological, clinical and neuroimaging features of $C 9$ orf72-related disorders.

\section{EPIDEMIOLOGICAL PROFILE}

The overall prevalence of ALS ranges from 2-7 cases per 100,000 inhabitants $^{1}$. A minor proportion of $5 \%$ of ALS cases represent familial autosomal dominant ALS cases ${ }^{8}$. In the last decade, SOD1 mutations were considered the most common genetic form of familial ALS ${ }^{1}$. However, great knowledge was obtained from new gene discovery allowing a more comprehensive approach in the previously unidentified familial cases. Mutations in the C9orf72 gene represent up to $50 \%-60 \%$ of cases of familial ALS and up $10 \%$ of sporadic ALS in some locations, but with an average of one third of familial cases ${ }^{9,10}$. It is also believed that most sporadic cases of ALS under the general assignment of unknown or unidentified genetic cause may be originated by C9orf72 mutations ${ }^{11,12}$.

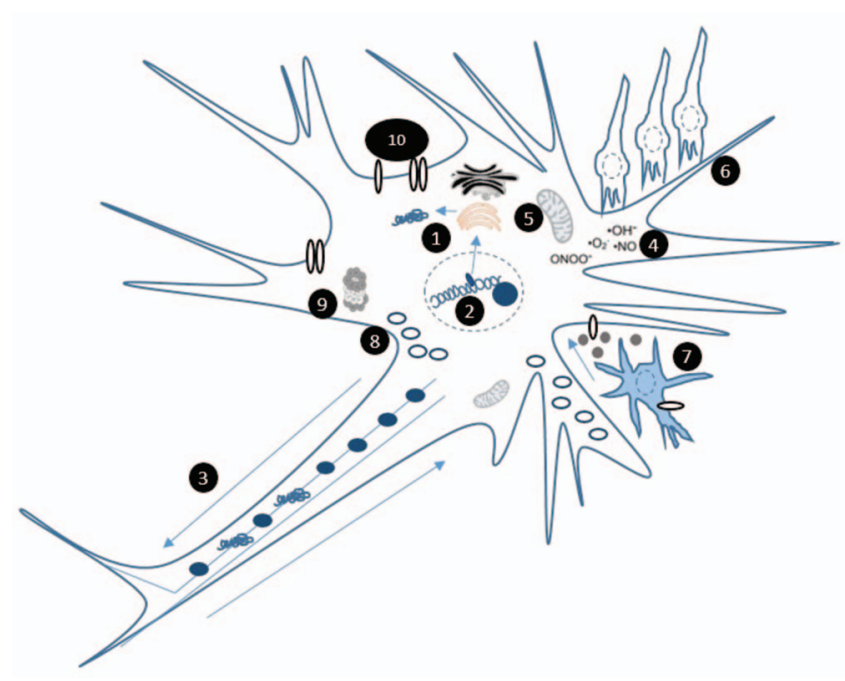

Figure 1. Schematic representation of the main pathophysiological mechanisms involved with motor neuron disease, (1) including protein misfolding, (2) altered RNA processing (mainly disturbed mRNA splicing), (3) defects in axonal transport, (4) abnormal accumulation of reactive oxygen species, (5) mitochondrial dysfunctions, (6) microglial neuroinflammatory mechanisms, (7) direct excitotoxicity by astrocytes, (8) disturbances of autophagy, (9) proteosome abnormalities and (10) ion channel defects.

FTD presents with a global average prevalence of 15-22 cases per 100,000 inhabitants. Around 40\%-50\% of FTD cases present with a positive family history of dementia, mainly with autosomal dominant inheritance pattern ${ }^{13}$. It is estimated that up to $18 \%-24 \%$ cases of familial FTD and $6 \%-10 \%$ of sporadic cases of bvFTD are due to C9orf72 expansions ${ }^{5,14,15}$.

C9orf72 repeat expansions have a wide global distribution, mainly in European-derived populations, and an exceptionally low prevalence in East Asian populations and probably in South and Southern Asia regions ${ }^{16}$. In cases of FTD in Europe (including patients from 15 countries), C9orf72 repeat expansions were detected with high frequency in Finland (29.3\% of all cases), in Spain (25.5\%) and in Sweden (20.7\%), and low prevalence was detected in Germany (4.8\%). In a large group of patients from USA, Europe and Australia, the overall C9orf72 prevalence was $7 \%$ of sporadic ALS, $39.3 \%$ of familial ALS, $6 \%$ of sporadic FTD and $24.8 \%$ of familial FTD $^{3}$. Other series form London patients with the FTD-ALS phenotype, $26 \%$ presented with the C9orf72 expansion followed by $24 \%$ in SOD1 gene, $4 \%$ in FUS gene and $1 \%$ in TARDPB gene ${ }^{17}$, showing that C9orf72 represents the most common genetic cause of familial cases of FTD-ALS in Europe ${ }^{18}$.

\section{GENETIC ASPECTS AND PATHOPHYSIOLOGY}

Familial and sporadic cases of ALS and FTD have been linked to several genomic regions, most related to one or 
Table 1. Genetic causes of frontotemporal dementia ${ }^{4,20,21}$.

\begin{tabular}{lc}
\hline Gene involved (locus) & Pattern of inheritance \\
\hline C9orf72 (Chromosome 9 Open Reading Frame 72; 9p21.2) & Autosomal dominant \\
GRN (Progranulin; 17q21.31) & Autosomal dominant (3\%-26\% of all cases) \\
VCP (Valosin-containing Protein; 9p13.3) & Autosomal dominant \\
TARDBP (TAR DNA-binding protein; 1p36.22) & Autosomal dominant \\
MAPT (Microtubule-associated Protein Tau; 17q21.31) & Autosomal dominant (40\%-50\% of all cases) \\
CHMP2B (Chromatin-modifying protein member 2B; 3p11.2) & Autosomal dominant \\
PSEN1 (Presenilin 1; 14q24.2) & Autosomal dominant \\
UBQLN2 (Ubiquilin 2; Xp11.21) & X-linked \\
CHCHD10 (Coiled-coil-helix-coiled-coil-helix-domain-containing protein 10; 22q11.23) & Autosomal dominant \\
\hline
\end{tabular}

more different mechanisms of neurodegeneration ${ }^{11,19,20}$. An extensive number of genes located in different chromosome regions and related to distinct patophysiological mechanisms have been linked to clinical and neuropathological findings of FTD and ALS (Tables 1 and 2) 4,11,14,20,21.

C9orf72 (chromosome 9 open reading frame 72) gene (MIM *614260) represents a reasonably recently described gene linked to sporadic and familial cases of neurodegenerative disorders. Heterozygous hexanucleotide repeat expansions in a noncoding region of the gene are responsible for its pathogenesis, in a similar pattern of other repeat expansion disorders $^{22,23,24}$ (Table 3). C9orf72-related disorders represent clinical and pathologically heterogeneous autosomal dominant neurodegenerative diseases with partial (or incomplete) penetrance, giving rise to pleiotropic manifestations. The pathogenic repeat expansion is fully penetrant around 80

Table 2. Genetic causes of amyotrophic lateral sclerosis (familial and sporadic cases) 11,14,20.

\begin{tabular}{|c|c|}
\hline Gene involved (locus) & Pattern of inheritance \\
\hline SOD1 (Superoxide dismutase 1; 21q22.11) & $\begin{array}{c}\text { Autosomal dominant or recessive (12\%-13\% of familial; } 2 \% \\
\text { of sporadic) }\end{array}$ \\
\hline C9orf72 (Chromosome 9 Open Reading Frame 72; 9p21.2) & Autosomal dominant \\
\hline FUS (Fused in Sarcoma; 16p11.2) & $\begin{array}{c}\text { Autosomal dominant or recessive ( } 5 \% \text { of familial; }<1 \% \text { of } \\
\text { sporadic) }\end{array}$ \\
\hline CHMP2B (Chromatin-modifying protein member 2B; 3p11.2) & Autosomal dominant \\
\hline ALS2 (Alsin; 2q33.1) & Autosomal recessive \\
\hline UBQLN2 (Ubiquilin 2; Xp11.21) & X-linked \\
\hline PFN1 (Profilin 1; 17p13.2) & Autosomal dominant \\
\hline OPTN (Optineurin; 10p13) & Autosomal recessive or dominant \\
\hline TARDBP (TAR DNA-binding protein; 1p36.22) & Autosomal dominant ( $5 \%$ of familial) \\
\hline SQSTM1 (Sequestosome 1; 5q35.3) & Autosomal dominant \\
\hline PRPH (Peripherin; 12q13.12) & Sporadic \\
\hline HNRNPA1 (Heterogeneous Nuclear Ribonucleoprotein A1; 12q13.13) & Autosomal dominant \\
\hline DCTN1 (Dynactin 1; 2p13.1) & Autosomal dominant \\
\hline ANG (Angiogenin; 14q11.2) & Autosomal dominant \\
\hline $\begin{array}{l}\text { FIG4 (FIG4, S. cerevisiae, homolog of SAC1 lipid phosphatase domain } \\
\text { containing; 6q21) }\end{array}$ & Autosomal dominant \\
\hline NEFH (Neurofilament protein, Heavy Polypeptide; 22q12.2) & Autosomal dominant \\
\hline VCP (Valosin-containing Protein; 9p13.3) & Autosomal dominant \\
\hline SETX (Senataxin; 9q34.13) & Autosomal dominant \\
\hline $\begin{array}{l}\text { ERRB4 (V-Erb-B2 avian erythroblastic leucemia viral oncogene homolog 4; } \\
\text { 2q34) }\end{array}$ & Autosomal dominant \\
\hline SIGMAR1 (Sigma Nonopioid Intracellular Receptor 1; 9p13.3) & Autosomal recessive \\
\hline $\begin{array}{l}\text { VAPB (Vesicle-associated Membrane Protein-associated Protein B; } \\
\text { 20q13.32) }\end{array}$ & Autosomal dominant \\
\hline MATR3 (Matrin-3; 5q31.2) & Autosomal dominant \\
\hline $\begin{array}{l}\text { CHCHD10 (Coiled-coil-helix-coiled-coil-helix-domain-containing protein 10; } \\
\text { 22q11.23) }\end{array}$ & Autosomal dominant \\
\hline DAO (D-amino acid oxidase; 12q24) & Autosomal dominant \\
\hline ATXN2 (ataxin 2; 12q24.12) & Autosomal dominant \\
\hline SMN1 (Survival of Motor Neuron 1; 5q13.2) & Autosomal dominant \\
\hline EWSR1 (Ewing sarcoma breakpoint region 1; 22q12.2) & Autosomal dominant \\
\hline $\begin{array}{l}\text { TAF15 (TAF15 RNA polymerase II, TATA box-binding protein-associated } \\
\text { factor, 68-kD; 17q12) }\end{array}$ & Autosomal dominant \\
\hline SPG11 (SPG11 gene/spatacsin; 15q21.1) & Autosomal recessive \\
\hline TUBA4A (Tubulin, alpha-4A; 2q35) & Autosomal dominant \\
\hline
\end{tabular}


Table 3. Clinical neurological diseases associated with the genetic mechanism of unstable nucleotide repeat expansion $22,23,24$

\begin{tabular}{|c|c|c|}
\hline $\begin{array}{l}\text { Class of nucleotide repeat } \\
\text { expansion }\end{array}$ & Neurological disorder (gene involved; locus) & $\begin{array}{c}\text { Nucleotide repeat sequence (pathological } \\
\text { number of repeats) }\end{array}$ \\
\hline \multirow{18}{*}{ Trinucleotide } & \multirow{4}{*}{$\begin{array}{c}\text { Fragile X syndrome (FRAXA) (FMR1; Xq27.3) } \\
\text { Fragile X tremor/ataxia syndrome (FXTAS) (FMR1; Xq27.3) } \\
\text { X-linked mental retardation associated with fragile site } \\
\text { (FRAXE) (FMR2/AFF2; Xq28) } \\
\text { Huntington's disease (HTT; 4p16.3) }\end{array}$} & CGG $(>200)$ \\
\hline & & CGG (55-200) \\
\hline & & CCG $(>200)$ \\
\hline & & CAG $(>37)$ \\
\hline & Huntington disease-like 2 (JPH3; 16q24.2) & CAG $(>41)$ \\
\hline & Friedreich's ataxia (FXN; 9q21.11) & GAA $(70->1000)$ \\
\hline & Spinocerebellar ataxia type 1 (ATXN1; 6p22.3) & CAG (40-83) \\
\hline & Spinocerebellar ataxia type 2 (ATXN2; 12q24.12) & CAG (32-79) \\
\hline & Spinocerebellar ataxia type 3 (ATXN3; 14q32.12) & CAG (52-86) \\
\hline & Spinocerebellar ataxia type 6 (CACNA1A; 19p13.2) & CAG (19-33) \\
\hline & Spinocerebellar ataxia type 7 (ATXN7; 3p14.1) & CAG (36-306) \\
\hline & Spinocerebellar ataxia type 8 (ATXN8 and ATXN8OS; 13q21) & $C T G * C A G(71-1300)$ \\
\hline & Spinocerebellar ataxia type 12 (PPP2R2B; 5q32) & CAG (51-78) \\
\hline & Spinocerebellar ataxia type 17 (TBP; 6q27) & CAG/CAA (47-63) \\
\hline & Dentatorubral-pallidoluysian atrophy (ATN1; 12p13.31) & CAG (49-93) \\
\hline & Kennedy disease $\left(A R ; \mathrm{Xq}_{12}\right)$ & CAG (38-62) \\
\hline & Myotonic dystrophy type 1 (DMPK; 19q13.32) & CTG $(>50)$ \\
\hline & Oculopharyngeal muscular dystrophy (PABPN1; 14q11.2) & GCG (12-17) \\
\hline Tetranucleotide & Myotonic dystrophy type 2 (ZNF9; 3q21.3) & CCTG $(75-11.000)$ \\
\hline Pentanucleotide & Spinocerebellar ataxia type 10 (ATXN10; 22q13.31) & АТTCT (400-4500) \\
\hline Hexanucleotide & Spinocerebellar ataxia type 36 (NOP56; 20p13) & GGCCTG (650-2500) \\
\hline & FTD \pm ALS (C9orf72; 9p21.2) & GGGGCC (250-1600) \\
\hline
\end{tabular}

years, but no penetrance is found in individuals younger than 35 years $^{3}$. In some cases, anticipation has been observed, but less prominent than in other expansion repeat expansion diseases. An european founder effect has been detected for the expansion in Scandinavia, more specifically in Finland ${ }^{16}$.

The C9orf72 gene is located on 9p21.2 and is formed by 12 exons, coding 3 transcription variants and two protein isoforms (a, b). Transcript variants 1 , which contains nonconding exons $1 \mathrm{~b}$, and 3 , which contains noncoding exon la, are fused to coding exons 2 through 5 and encode a longer isoform of the protein with 481 amino acid (called isoform a). Transcript variant 2, which contains exon 1a, encodes a shorter protein with 222 amino acid (called isoform b), highly expressed in testis, fetal brain, cerebellum and frontal cortex ${ }^{16}$.

The expansion site is located in the 5' regulatory region upstream of the transcription start site between two noncoding exons $(1 \mathrm{a}, 1 \mathrm{~b})$ in the core promoter for transcript variant 1 , leading to haploinsufficiency mechanism with variable degrees of reduction of isoform a. For transcription variants 2 and 3, the expansion is located in intron 1, leading to aberrant and abnormal production with classical gain-offunction mechanisms participating in toxic pathogenetic mechanisms and influencing the processing of precursor mRNAs (Figure 2). Hexanucleotide repeat expansion also forms DNA and RNA G-quadruplexes which promotes the formation of RNA/DNA hybrids (R-loops), originating a repeat length-dependent accumulation of transcripts which bind to ribonucleoproteins, such as nucleolin, giving rise to nucleolar stress ${ }^{16,25}$.

Loss-of-function by means of happloinsufficiency represents the main mechanism involved in its pathogenesis (Figure 3). The C9orf72 encoded protein is found in presynaptic terminals and cytoplasmic regions of neurons in a diffuse pattern and is still poorly understood. One of the main hypotheses regarding its function propose a similar function to guanine nucleotide exchange factors for small GTPases associated with the regulation of Rab protein system during endosomal trafficking regulation of exocytosis and endocytosis (with the Rab protein system) in neuronal cell lines, primary cortical neurons and spinal cord motor neurons. It gives rise to a higher rate of lysosomal protein degradation and abnormal accumulation of ubiquinated proteins ${ }^{26}$. The C9orf72 encoded protein also participates in mechanisms of neuronal autophagic process and interacts with nuclear proteins involved with regulation of splicing and RNA metabolism $^{18}$.

C9orf72 expansion-mediated toxicity occurs by accumulation of toxic RNA foci and RNA-binding proteins with secondary dysregulation of RNA splicing and trafficking, and inappropriate formation of novel dipeptide aggregates resulting from non-ATG mediated (RAN) translation of the hexanucleotide repeat (colocalized with p62+ inclusions) ${ }^{27}$. Most cases result from gain-of-function mechanisms directly related or not to the encoded protein. RNA-mediated cytotoxic nuclear and cytoplasmic mechanisms may occur first 


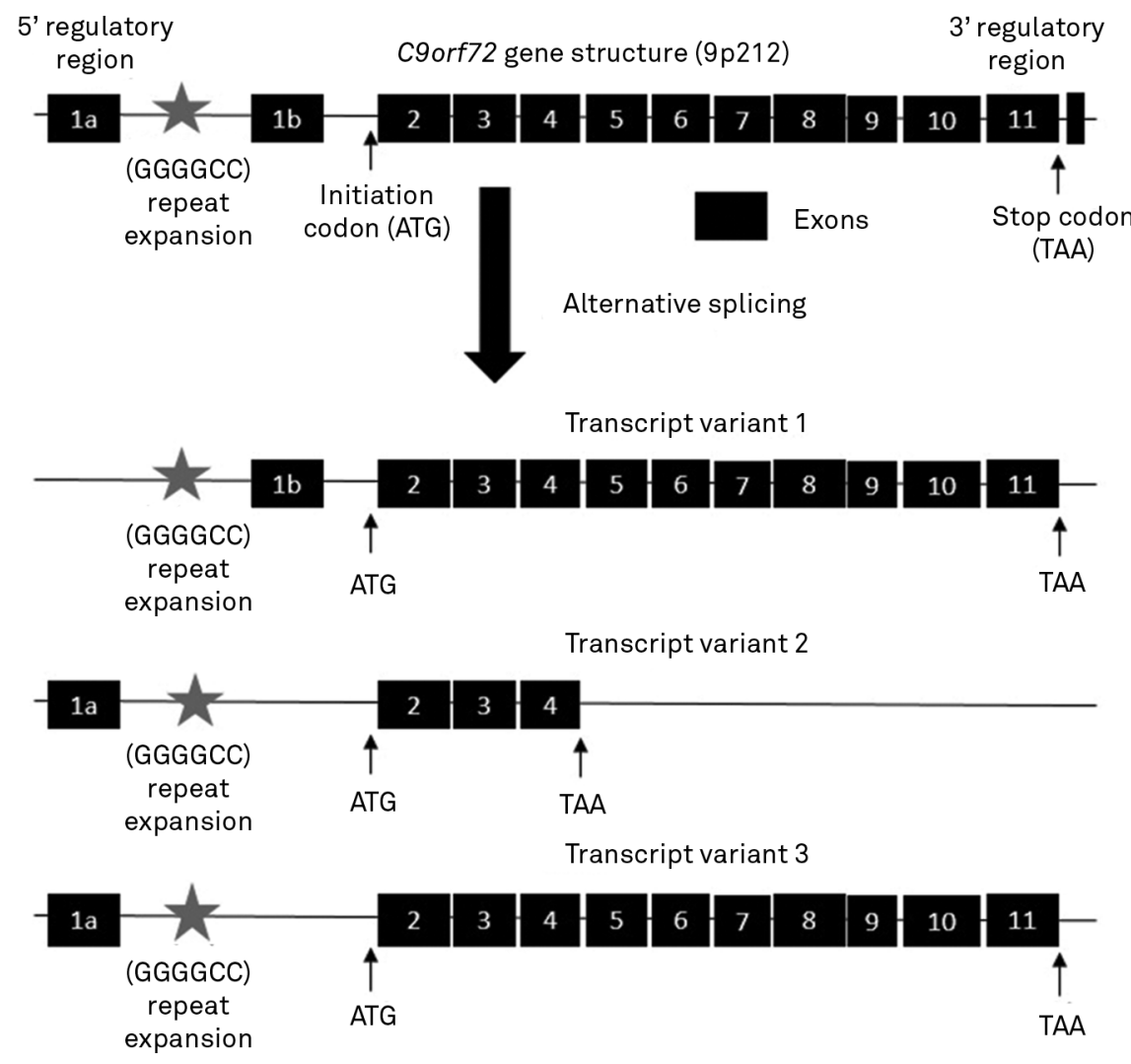

Figure 2. Schematic representation of C9orf72 gene structure and its transcript variants produced by alternative splicing.

in astrocytes and result from RNA foci formation, not found proteasome dysfunction, commonly found in C9orf72-related in sporadic ALS or familial FTD-ALS causes by other gene ALS and FTD cases. Genetic instability, dysfunction of the mutations ${ }^{28,29}$. Aggregate formation occur mainly through promoter region, abnormal mRNA distribution, splicing

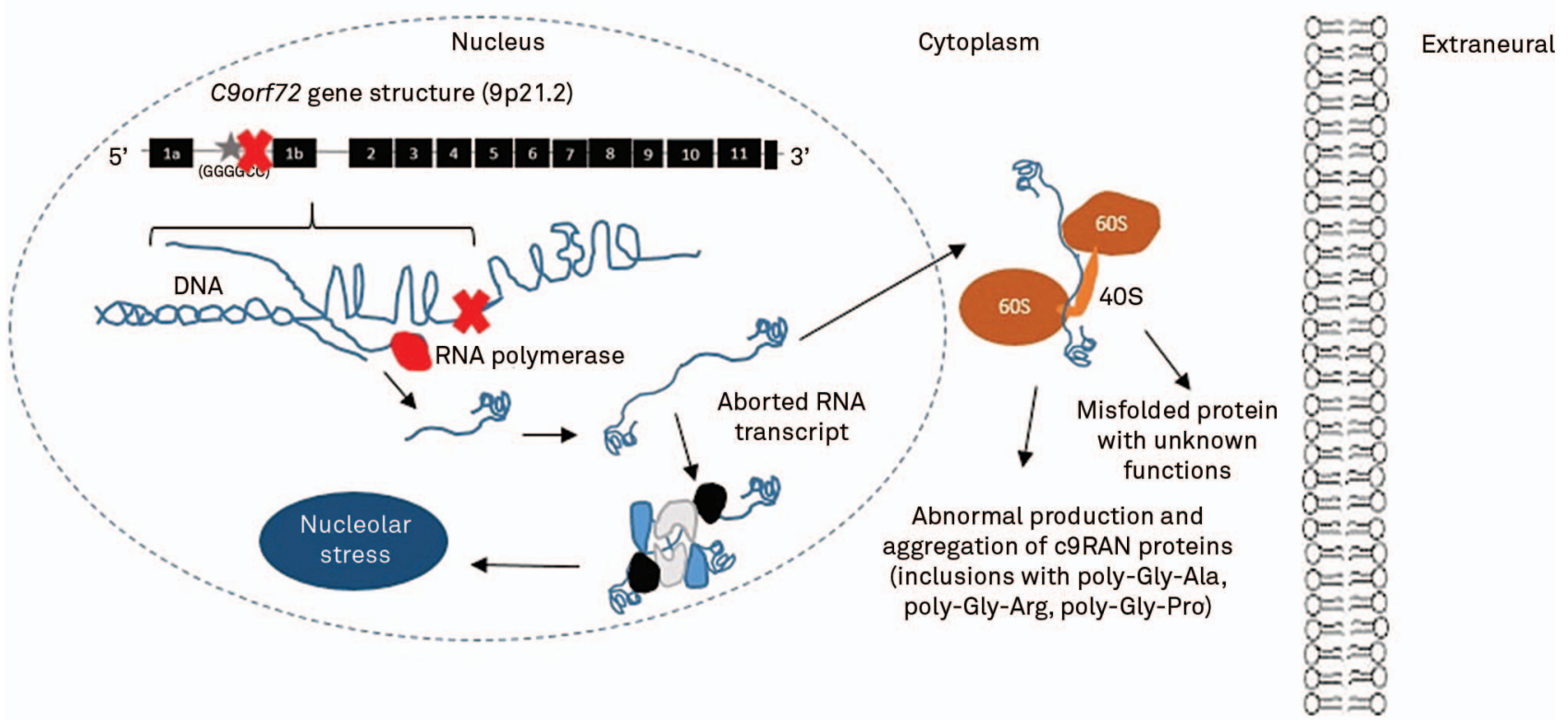

Figure 3. Pathophysiological mechanisms involved with abnormal RNA processing in C9orf72-related disorders. The aborted RNA transcript can migrate to cytoplasm and give rise rybosomal traduction of abnormal misfolded protein with unknown functions and originate aggregates of C9-related abnormal proteins, frequently seen in immunohistochemical analysis as intraneuronal intracytoplasmic inclusions. The aborted RNA transcript can also participate in complex intranuclear interactions and promote nucleolar stress. Both mechanisms participate as particular pathophysiological mechanisms seen in C9orf72-related FTD-ALS. 
and translation are also linked to the formation of G-quadruplexes (or G-tetrads) of uni and multimolecular $\mathrm{RNA}^{24}$. Besides this intraneuronal mechanisms, it has been demonstrated that ALS patients carrying C9orf72 mutations have astrocytes that convey toxicity towards motor neurons ${ }^{30}$.

The so-called GGGGCC $(\mathrm{G} 4 \mathrm{C} 2)_{\mathrm{n}}$ hexanucleotide repeat expansion, in the normal asymptomatic individual, ranges from 2 to 19 repeats, despite the fact of up to 30 repeats being also considered normal. However, asymptomatic patients have also been described in cases with the repeats in the pathogenic interval. Symptomatic patients are described in cases with more than 30 repeats, generally with 250 to 1,600 repeats, and more symptomatic in cases with more than 400 repeats $^{16,19}$.

\section{NEUROPATHOLOGICAL ASPECTS}

Neuropathological studies have been widely performed in C9orf72-related disorders. Gross pathology examination generally shows global brain atrophy, particularly of the frontal and temporal lobes with mild to moderate subcortical involvement. Microscopic evaluation unveils neuronal degeneration and loss with variable degrees of gliosis and superficial laminar spongiosis (depending on disease stage), but rarely with Pick bodies and with relative paucity of amyloid plaques and neurofibrillary tangles. Myelin loss in the corticospinal tracts with moderate to severe degeneration of the motor system is also described in cases of FTD even without clinical features of motor neuron disease ${ }^{9,19}$. Marked loss of lower motor neurons in cranial nerve motor nuclei in the brainstem (mainly in the medulla) and in the anterior horns of the spinal cord with marked microglial reaction is observed in all levels of the pyramidal tract in cases with associated ALS phenotype ${ }^{19}$.

Immunohistochemistry patterns represent important findings in C9orf72 neuropathological studies. The finding of TDP-43 (TAR/transactive response DNA-binding protein 43) positive cytoplasmic inclusions in spinal motor neurons and eventually in glial cells, commonly associated with cytoplasmic neuronal ubiquitin-positive and Tau-negative inclusions in the cortex and spinal cord ${ }^{19,31,32}$. The absence of FUS and Ubiquilin 2 positive inclusions differentiate C9orf72 spectrum from other genetic forms of FTD-ALS disorders ${ }^{14}$.

Another highly specific, nearly pathognomonic, molecular signature of C9orf72-related neuropathology is the finding of TDP-43 negative and p62-positive neuronal cytoplasmic inclusions in extra-motor regions within the dentate gyrus granule cells, in the CA4 pyramidal cells of the hyppocampus, in the frontal neocortex and in granule cells of the cerebellum $^{19,33}$. These represent dipeptide repeat proteins, previously described, formed as a result of sense and antisense repeat associated non ATG-initiated translation of the expanded repeat noncoding region ${ }^{9,27}$. Dopaminergic neuron loss in substantia nigra is also common in C9orf72 cases of ALS with p62-positive inclusions and without $\alpha$ synuclein-positive Lewy bodies thus in a distinct pattern of involvement than in idiopathic Parkinson disease ${ }^{34}$.

Although classically described in motor neurons in anterior horn of the spinal cord in ALS cases and rarely in association with atypical Pick's disease, eosinophilic intraneuronal inclusions rich in transferrin and cystatin $\mathrm{C}$, the so-called Bunina bodies, have also been reported in cases of FTD-ALS in C9orf72-related repeat expansion, despite not representing a significant finding in this context ${ }^{35}$.

\section{CLINICAL AND LABORATORY CHARACTERIZATION}

The association of ALS and FTD with other neurological phenotypes is widely known from the past ${ }^{36}$, including the first descriptions of FTD-ALS complex about 40 years ago. C9orf72 repeat expansions are involved with a wide spectrum of neurological manifestations ${ }^{37,38}$, involving motor and nonmotor (cognitive and behavioral) phenotypes (syndromes) ) $^{38}$ (Figure 4). Most clinical data come from populational studies in European countries and in US. It is possible to extend concepts obtained from the analysis of such populations to propose a proper overall analysis. Hexanucleotide repeat expansions in C9orf72 gene have been described in different contexts of neurodegenerative syndromes, ranging from classical bvFTD to sporadic Creutzfeldt-Jakob disease-like phenotype ${ }^{39}$. Few data regarding Brazilian patients with C9orf72-related disorders exist, but in general presenting with classical behavioural and extrapyramidal (focal dystonia, parkinsonism) compromise findings ${ }^{40}$.

Since 2011, C9orf72 gene has become a leading figure in the genetics of neurodegenerative processes involving motor neuron disease and dementia. There is frequent misunderstood regarding the FTD-ALS complex and the lytico-bodig disease or amyotrophic lateral sclerosis-parkinsonismdementia complex, previously described in the Chamorro population from Guam Island in USA. The clinical picture arises from mutations in the TRPM7 gene (Transient receptor potential cation channel, subfamily $M$, member 7; 15q21.2), as a consequence from direct exposure to the neurotoxic effects of $\beta$-methylamino-L-alanine found in local Guam species of flying fox (Pteropus tokudae) ${ }^{41}$.

The most common clinical presentation related to C9orf72 is represented by adult-onset of bvFTD phenotype followed in the disease course by variable signs of a motor neuron disease, resembling $\mathrm{ALS}^{5}$. Semantic dementia and progressive non-fluent aphasia have rarely been described in association with motor neuron signs ${ }^{9}$, but might not exclude the hypothesis of C9orf72 gene hexanucleotide repeat expansion ${ }^{13}$. Neuropsychiatric profile involves early 


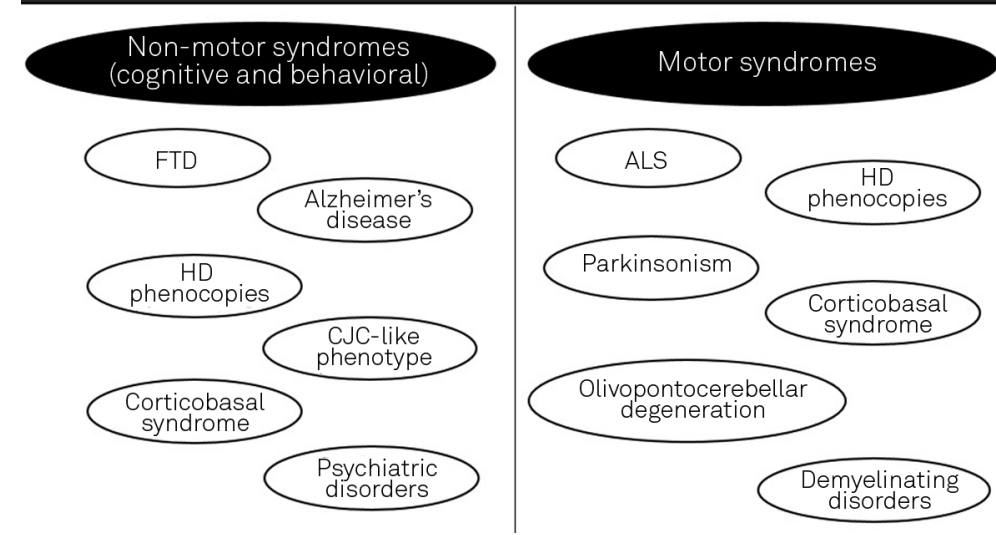

Figure 4. Summary of motor and non-motor (cognitive and behavioral) syndromes associated with C9orf72 gene hexanucleotide repeat expansion. FTD: Frontotemporal dementia; ALS: Amyotrophic lateral sclerosis; HD: Huntington disease; CJD: Creutzfeldt-Jakob disease.

disinhibition (up to 85\%), lack of insight (up to 78\%), hallucinations (up to 50\%), delusion (up to 50\%), anxiety (up to $52 \%$ ), hyperorality (up to $100 \%$ ), early apathy (up to $100 \%$ ), loss of empathy (up to 77\%) and obsessive-compulsive symptoms (up to $12 \%)^{5,42,43}$. There is an important clinical overlap with probable Alzheimer's disease in the early-onset cases, mainly in Caucasian patients ${ }^{45,46}$, making it difficult to promote a proper genetic evaluation in association with classical genes (APP, PSEN1, PSEN2) $)^{47,48}$, although such cases generally present with an older age than with the FTD clinical spectrum ${ }^{26}$. UBQLN2 gene mutations are great mimickers frequently differentiated in clinical means by the absence of psychiatric features (not behavioural symptoms) and lower motor neuron involvement ${ }^{14}$. In cases with pleiotropic heterogeneous phenotypic variability of repeat expansions, association with previously described pathogenic mutations in GRN or MAPT genes must be done ${ }^{49}$.

During the natural history of ALS, up to $50 \%$ of patients have cognitive decline, but only $15 \%-20 \%$ full-fill clinical criteria for $\mathrm{FTD}^{10,14}$. In $C 9$ orf 72 related ALS, despite the prevalence of $35 \%$ with at least one family member with dementia $^{19}$ and the higher rate of cognitive dysfunction, the most significant manifestations include psychiatric symptoms (delusions and hallucinations) and higher rates of familial members with parkinsonism ${ }^{8}$.

There are no specific clinical hallmarks which differentiate FTD and ALS phenotypes linked to C9orf72 to those associated with other genes. C9orf72-spectrum disorders tend to have a lower age of onset, shorter survival, more rapid clinical course, bulbar symptoms at onset (in cases of ALS phenotype), propensity toward psychosis, early-onset delusions (up to 45\%), paranoia or late-onset hallucinations (up to 50\%). Early-onset delusion in the context of ALS is highly suggestive of $C 9$ orf72 expansions ${ }^{5}$, despite the absence of a specific neuropsychiatric symptom pattern ${ }^{2}$. There is also an increased incidence of neurodegenerative disease in relatives (mainly dementia in $33 \%$ of cases) when compared to patients with other forms of ALS or FTD, even in the rare cases without clear cognitive dysfunction ${ }^{5,9,10,19}$.

Parkinsonism is a key feature in C9orf72-spectrum phenotype. Early-onset mild parkinsonism (mainly akinetic-rigid) with focal dystonia and poor response to levodopa is the typical clinical picture, rarely presenting with diffuse Lewy body dementia parkinsonism. It is also documented the predisposition of some populations to parkinsonism in cases of C9orf72 repeat expansion ${ }^{12}$. Atypical parkinsonism with cerebellar ataxia mimicking multiple system atrophy has also been described $^{49}$, the same way as cerebellar ataxia with retained reflexes $^{50}$ and isolated olivopontocerebellar atrophy with hot-cross bun sign in the pons ${ }^{26,51}$. Due to its exceptionality, cerebellar ataxia as a clinical manifestations of C9orf72 expansion should be suspected only in cases with proper familial dementia or especially with motor neuron disease. There are no specific repeat intervals involved with atypical parkinsonism and cerebellar ataxia ${ }^{26}$.

Another phenotype on growing evidence and importance is represented by Huntington's disease (HD) phenocopies, cases in which typical or suspected cases of HD present with negative genetic testing ${ }^{52}$ (Table 4). Most cases studied presented with earlier age at onset and a different combination of movement disorders, including dystonia, tremor, rigidity, myoclonus and chorea, thus with a broader spectrum than HD classical phenotype. One highly suggestive clinical context is the presence of upper motor neuron features in cases of HD-like phenotype. ALS-like phenotype mainly with lower motor neuron signs in this context is rarely associated with the HD, FTD and C9orf72 clinical spectrum. There is no specific size of repeat expansion linked to this phenotype, making part of the set of most expansion sizes in other clinical situations linked to $C 90 r f 72^{53}$. 
Table 4. Differential diagnoses of genetic causes of Huntington's disease-like syndromes ${ }^{52}$.

\begin{tabular}{|c|c|c|}
\hline \multicolumn{3}{|c|}{ Groups of neurological conditions linked to Huntington's disease phenocopies } \\
\hline । & $\begin{array}{l}\text { Classical Huntington } \\
\text { disease-like }\end{array}$ & Huntington disease-like types 1, 2, 3 \\
\hline ॥ & Degenerative ataxias & $\begin{array}{c}\text { Ataxia-telangiectasia, Ataxia-telangiectasia-like disorder; Ataxia with oculomotor } \\
\text { apraxia types 1, 2, 3; Friedreich ataxia; Dentatorubral-Pallidoluysian atrophy; } \\
\text { Spinocerebellar ataxias types } 1,2,7,8,14,17\end{array}$ \\
\hline III & Neurometabolic disorder & $\begin{array}{l}\text { Aceruloplasminemia, Wilson disease, Lesch-Nyhan syndrome } \\
\text { C9orf72-related disoders, Neuroferritinopathy (Neurodegeneration with Brain }\end{array}$ \\
\hline IV & Miscellanea & $\begin{array}{c}\text { Iron Accumulation type 3), Pantothenate Kinase-Associated Neurodegeneration } \\
\text { (Neurodegeneration with Brain Iron Accumulation type 1), Neuroacanthocytosis } \\
\text { type McLeod, Choreoacanthocytosis, Kufor-Rakeb syndrome }\end{array}$ \\
\hline
\end{tabular}

During a large screening for genetic causes of early-onset autosomal dominant inherited dementia, atypical clinical presentations of $C 9$ orf72-related disease were found and disclosed a rare presentation of an olivopontocerebellar degeneration and a corticobasal syndrome-like phenotype ${ }^{51}$. Visuospatial dysfunction has also been described, but the phenotype of pure spastic paraparesis is not associated with repeat expansion ${ }^{38}$. It has also been identified a higher prevalence of multiple sclerosis within families with ALS, mainly those associated with C9orf $72^{19}$.

It has also been described an uncommon psychiatric phenotype with familial bipolar disorder with C9orf72 expansion with one family member with late-onset features which progressed to frontotemporal lobe degeneration ${ }^{54}$. Repeat expansions were rarely described in cases of men with refractory depression that harboured a previous suspected diagnosis of depressive pseudodementia ${ }^{55}$. Some authors even suggest the possibility of performing C9orf72 gene evaluation in cases of late-onset psychosis ${ }^{56}$. Suicide attempt is also a clinical presentation linked to the repeat expansion. Those carrying the C9orf72 repeat expansion are also more likely to have family members with neuropsychiatric conditions, including psychosis and a history of suicide ${ }^{57}$.

General serum laboratory profile is completely normal. Expansions can be properly detected with repeat-primed PCR and Southern blotting approaches. Large series of electroneuromyographic pattern evaluations and muscle biopsies in C9orf72 have not been studied, but do not differ from sporadic cases of ALS without this same genetic profile. No specific CSF examination findings and biomarkers are available and most range usually in normal levels (beta amyloid, tau, phosphorylated tau, tau-to-beta amyloid ratio), although some patients present with an Alzheimer's disease-like CSF profile ${ }^{16}$.

\section{NEUROIMAGING STUDIES}

There is a wide radiological and pathological correlation in cases of $C 9$ orf72. However, no pathognomonic findings on cranial CT and brain MRI have been described ${ }^{2}$. Most neuroimaging descriptions were performed in cases linked to any degree of cognitive of compromise or behavioral disturbances. Symmetrical frontal and temporal lobe, insular, and posterior cortical (parietal and occipital) atrophy are the rule mainly when associated with subcortical involvement of the thalamus and cerebellum, rarely described in other genetic forms of FTD and which tend to progress and accent during disease course (Figure 5). The degree of temporal involvement may be less prominent than that seen in other genetic causes of FTD, despite severe clinical involvement. One notorious exception with predominant temporal atrophy is represented by C9orf72-related cases with primary progressive aphasia phenotype ${ }^{58}$. The finding of hot-cross bun sign in the pons has also been described in the context of C9orf72-spectrum in a single case of late-onset cerebellar variant of multiple system atrophylike phenotype ${ }^{49}$.

In cases of C9orf72-related ALS, volumetry and morphometry brain MRI studies also disclosed prominent atrophy of right inferior and superior frontal gyri, right precentral gyri and left anterior cingulate cortex ${ }^{10}$. The same group of changes linked to the FTD phenotype are also present in the ALS phenotype ${ }^{9}$, although the presence of bilateral thalamic atrophy is rarely described in cases of isolated ALS phenotype ${ }^{59}$. The presence of the "bright tongue sign" in the context of a frontotemporal dementia points to the possibility of associated motor neuron disease ${ }^{60}$.

No specific or highly-suggestive patterns have been described in positron emission tomography (PET) and single-photon emission computed tomography (SPECT). However, some pathological changes have been pointed out. SPECT shows hypoperfusion in the anterior and middle cingulate gyri, and variable degrees of frontal cortical hypometabolism in PET, although these findings do not represent a rule and depend on disease stage of evolution ${ }^{58}$.

It is also possible to differentiate general neuroimaging patterns in the FTD spectrum with impaired C9orf72 with other high prevalence genes as GRN and MAPT. Exceptionally mutations in these genes originate thalamic and cerebellar atrophy, which represents important differential diagnostic findings. $G R N$ gene mutations are commonly 

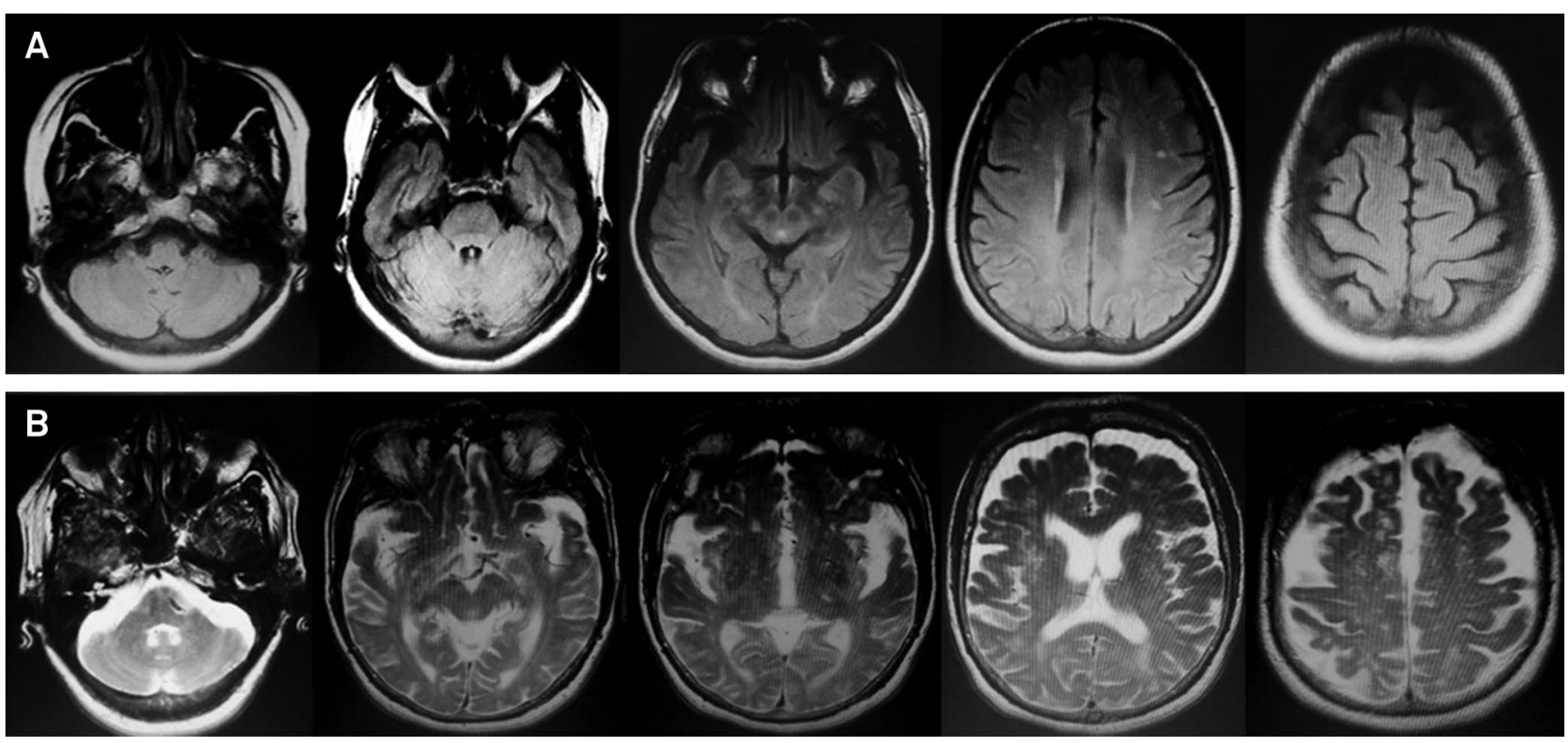

Figure 5. Neuroimaging features described during early (A) and advanced (B) stages of C9orf72-related spectrum disorders. (A) Axial FLAIR-weighted brain MRI disclosing early stage changes represented by mild frontal and temporal lobe atrophy; and (B) Axial T2-weighted brain MRI disclosing a typical end-stage pattern represented by marked symmetrical frontal and temporal atrophy with cerebellar and thalamic atrophy.

associated with asymmetric hemispheric atrophy, predominantly in the inferior frontal, superior temporal and inferior parietal gyri, eventually associated with any degree of leukoencephalopathy. MAPT gene mutations are associated with symmetric frontotemporal atrophy, predominantly in the anterior and medial portions of the temporal lobes, the fornix and orbitofrontal cortex, possibly with cerebellar involvement $^{10,58}$.

\section{THERAPEUTIC PERSPECTIVES}

Symptomatic therapy remains the exclusive drug measure in cases of FTD and ALS besides the proper use of multidisciplinary approaches. Developing new therapy modalities provide new multimodal treatment perspectives for most inherited and sporadic cases of FTD-ALS patients. Most data regarding C9orf72-targeted therapies derive from other repeat expansion neurodegenerative disorders. New disease-modifying therapies are being studied as new attempts on ALS and FTD therapeutics rather than neuroprotective approaches. However, few specific clinical trials, none exclusively with C9orf72 mutations.

Dexpramipexole, Riluzole and Fingolimod represent neuroprotective perspectives in cases of FTD-ALS ${ }^{13}$. Patient-specific induced pluripotent stem cell therapy, immunotherapies, antioxidant agents, minocycline, insulinlike growth factor-1 (IGF-1) and lithium carbonate are other alternative treatment options used in preclinical studies ${ }^{13,14}$. Most recent attempts target mRNA dysfunctions in FTDALS, mainly the aberrant splicing process, the nuclear RNA-binding proteins and contentes from nuclear inclusions. The use of antisense oligonucleotides to silence targeted mRNA or to modulate splicing represents an important perspective in the therapy of C9orf72-related disorders, applying clinical research data obtained from muscular dystrophies, spinocerebellar ataxias and chronic lymphocytic leukemia ${ }^{14,29}$.

\section{CONCLUSION}

The spectrum of neurological conditions associated with hexanucleotide repeat expansion of C9orf72 gene is very broad, ranging from the classic phenotype of motor neuron disease and frontotemporal dementia to the most recently descriptions of parkinsonian syndromes, Huntington's disease-like phenocopies, Alzheimer's disease-like phenotypes and rarely cerebellar ataxias and other psychiatric disorders. Extensive studies of neuroimaging, molecular neurogenetics and neuropathology allowed the knowledge of specific information related to C9orf72 phenotypes. Clinicians must be aware about such clinical and neuroimaging spectrum related to C9orf72 for proper investigation of suspected cases in the setting of neurodegenerative disorders. 
1. Oliveira AS, Pereira RD. Amyotrophic lateral sclerosis (ALS): three letters that change the people's life. For ever. Arq Neuropsiquiatr. 2009;67(3A):750-82. http://dx.doi.org/10.1590/ S0004-282X2009000400040

2. Kaivorinne AL, Bode MK, Paavola L, Tuominen H, Kallio M, Renton AE et al. Clinical characteristics of C9ORF72-linked frontotemporal lobar degeneration. Dement Geriatr Cogn Dis Extra. 2013;3(1):251-62. http://dx.doi.org/10.1159/000351859

3. Majounie E, Renton AE, Mok K, Dopper EG, Waite A, Rollinson S et al. Frequency of the C9orf72 hexanucleotide repeat expansion in patients with amyotrophic lateral sclerosis and frontotemporal dementia: a cross-sectional study. Lancet Neurol. 2012;11(4):323-30. http://dx.doi. org/10.1016/S1474-4422(12)70043-1

4. Rademakers R, Neumann M, Mackenzie IR. Recent advances in the molecular basis of frontotemporal dementia. Nat Rev Neurol. 2012;8(8):423-34. http://dx.doi.org/10.1038/nrneurol.2012.117

5. Takada LT, Sha SJ. Neuropsychiatric features of C9orf72-associated behavioral variant frontotemporal dementia and frontotemporal dementia with motor neuron disease. Alzheimers Res Ther. 2012;4(5):38. http://dx.doi.org/10.1186/alzrt141

6. DeJesus-Hernandez M, Mackenzie IR, Boeve BF, Boxer Al, Baker M, Rutherford NJ et al. Expanded GGGGCC hexanucleotide repeat in noncoding region of C90RF72 causes chromosome 9p-linked FTD and ALS. Neuron. 2011;72(2):245-56. http://dx.doi.org/10.1016/j. neuron.2011.09.011

7. Renton AE, Majounie E, Waite A, Simón-Sánchez J, Rollinson S, Gibbs $\mathrm{JR}$ et al. A hexanucleotide repeat expansion in C90RF72 is the cause of chromosome 9p21-linked ALS-FTD. Neuron. 2011;72(2):257-68. http://dx.doi.org/10.1016/j.neuron.2011.09.010

8. Chiò A, Borghero G, Restagno G, Mora G, Drepper C, Traynor BJ et al. Clinical characteristics of patients with familial amyotrophic lateral sclerosis carrying the pathogenic GGGGCC hexanucleotide repeat expansion of C9ORF72. Brain. 2012;135(Pt 3):784-93. http://dx.doi. org/10.1093/brain/awr366

9. Hodges J. Familial frontotemporal dementia and amyotrophic lateral sclerosis associated with the C9ORF72 hexanucleotide repeat. Brain. 2012;135(3):652-5. http://dx.doi.org/10.1093/brain/aws033

10. Al-Chalabi A., Hardiman O. The epidemiology of ALS: a conspiracy of genes, environment and time. Nat Rev Neurol. 2013;9(11):617-28. http://dx.doi.org/10.1038/nrneurol.2013.203

11. Renton AE, Chiò A, Traynor BJ. State of play in amyotrophic lateral sclerosis genetics. Nat Neurosci. 2014;17(1):17-23. http://dx.doi.org/ $10.1038 / \mathrm{nn} .3584$

12. Rheenen W, Blitterswijk M, Huisman MH, Vlam L, Doormaal PT, Seelen $M$ et al. Hexanucleotide repeat expansions in C90RF72 in the spectrum of motor neuron diseases. Neurology. 2012;79(9):878-82. http://dx.doi.org/10.1212/WNL.0b013e3182661d14

13. Sha SJ, Boxer A. Treatment implications of C9ORF72. Alzheimers Res Ther. 2012;4(6):46. http://dx.doi.org/10.1186/alzrt149

14. Fernandes SA, Douglas AG, Varela MA, Wood MJ, Aoki Y. Oligonucleotide-based therapy for FTD/ALS caused by the C9orf72 repeat expansion: a perspective. J Nucleic Acids. 2013;2013:208245. http://dx.doi.org/10.1155/2013/208245

15. Zee J, Gijselinck I, Dillen L, Van Langenhove T, Theuns J, Engelborghs $S$ et al. A pan-European study of the C9orf72 repeat associated with FTLD: geographic prevalence, genomic instability, and intermediate repeats. Hum Mutat. 2013;34(2):363-73. http://dx.doi.org/10.1002/ humu. 22244

16. Woollacott 10, Mead S. The C9ORF72 expansion mutation: gene structure, phenotypic and diagnostic issues. Acta Neuropathol. 2014;127(3):319-32. http://dx.doi.org/10.1007/s00401-014-1253-7
17. Smith BN, Newhouse S, Shatunov A, Vance C, Topp S, Johnson L et al. The C9ORF72 expansion mutation is a common cause of ALS +/-FTD in Europe and has a single founder. Eur J Hum Genet. 2013;21(1):102-8. http://dx.doi.org/10.1038/ejhg.2012.98

18. Farg MA, Sundaramoorthy V, Sultana JM, Yang S, Atkinson RA, Levina $\checkmark$ et al. C9ORF72, implicated in amyotrophic lateral sclerosis and frontotemporal dementia, regulates endosomal trafficking. Hum Mol Genet. 2014;23(13):3579-95. http://dx.doi.org/10.1093/hmg/ddu06

19. Cooper-Knock J, Hewitt C, Highley JR, Brockington A, Milano A, Man $S$ et al. Clinico-pathological features in amyotrophic lateral sclerosis with expansions in C90RF72. Brain. 2012;135(Pt 3):751-64. http://dx.doi.org/10.1093/brain/awr365

20. He J, Mangelsdorf M, Fan D, Bartlett P, Brown MA. Amyotrophic lateral sclerosis genetic studies: from genome-wide association mapping to genome sequencing. Neuroscientist 2014 Nov 5. pii: 1073858414555404. [Epub ahead of print]. doi: 10.1177/ 1073858414555404

21. Van Langenhove T, Zee J, Van Broeckhoven C. The molecular basis of the frontotemporal lobar degeneration-amyotrophic lateral sclerosis spectrum. Ann Med. 2012;44(8):817-28. http://dx.doi.org/10.3109/ 07853890.2012 .665471

22. La Spada AR, Taylor JP. Repeat expansion disease: progress and puzzles in disease pathogenesis. Nat Rev Genet. 2010;11(4):247-58. http://dx.doi.org/10.1038/nrg2748

23. Gatchel JR, Zoghbi HY. Diseases of unstable repeat expansion: mechanisms and common principles. Nat Rev Genet. 2005;6(10):743-55. http://dx.doi.org/10.1038/nrg1691

24. Van Blitterswijk M, DeJesus-Hernandez M, Rademakers R. How do C90RF72 repeat expansions cause ALS and FTD: can we learn from other non-coding repeat expansion disorders? Curr Opin Neurol. 2012;25:689-700. http://dx.doi.org/10.1097/WC0.0b013e32835a3efb

25. Reddy K, Zamiri B, Stanley SYR, Macgregor Jr RB, Pearson CE. The disease-associated $r(G G G G C C)$ n repeat from the C9orf72 gene forms tract length-dependent uni- and multimolecular RNA G-quadruplex structures. J Biol Chem. 2013;288(14):9860-6. http://dx.doi.org/ 10.1074/jbc.C113.452532

26. Yokoyama JS, Sirkis DW, Miller BL. C9ORF72 hexanucleotide repeats in behavioral and motor neuron disease: clinical heterogeneity and pathological diversity. Am J Neurodegener Dis. 2014;3(1):1-18. http://dx.doi.org/10.1186/2051-5960-2-70

27. Davidson YS, Barker H, Robinson AC, Thompson JC, Harris J, Troakes $\mathrm{C}$ et al. Brain distribution of dipeptide repeat proteins in frontotemporal lobar degeneration and motor neurone disease associated with expansions in C9ORF72. Acta Neuropathol Commun. 2014;2(1):70.

28. Cruts M, Gijselinck I, Van Langenhove T, van der Zee J, Van Broeckhoven C. Current insights into the C9orf72 repeat expansion diseases of the FTLD/ALS spectrum. Trends Neurosci. 2013;36(8):450-9. http://dx.doi.org/10.1016/j.tins.2013.04.010

29. Lagier-Tourenne C, Baughn M, Rigo F, Sun S, Liu P, Li HR et al. Targeted degradation of sense and antisense C9orf72 RNA foci as therapy for ALS and frontotemporal degeneration. Proc Natl Acad Sci U S A. 2013;110(47):E4530-9. http://dx.doi.org/10.1073/pnas.1318835110

30. Meyer K, Ferraiuolo L, Miranda CJ, Likhite S, McElroy S, Renusch S et al. Direct conversion of patient fibroblasts demonstrates non-cell autonomous toxicity of astrocytes to motor neurons in familial and sporadic ALS. Proc Natl Acad Sci USA. 2014;111(2):829-32. http://dx.doi.org/10.1073/pnas.1314085111

31. Hsiung GY, DeJesus-Hernandez M, Feldman HH, Sengdy P, BouchardKerr P, Dwosh E et al. Clinical and pathological features of familial frontotemporal dementia caused by C90RF72 mutation on chromosome 9p. Brain. 2012;135(3):709-22. http://dx.doi.org/10.1093/ brain/awr354 
32. Murray ME, DeJesus-Hernandez M, Rutherford NJ, Baker M, Duara R, Graff-Radford NR et al. Clinical and neuropathologic heterogeneity of C9FTD/ALS associated with hexanucleotide repeat expansion in C9ORF72. Acta Neuropathol. 2011;122(6):673-90. http://dx.doi.org/ 10.1007/s00401-011-0907-y

33. Stewart H, Rutherford NJ, Briemberg H, Krieger C, Cashman N, Fabros $\mathrm{M}$ et al. Clinical and pathological features of amyotrophic lateral sclerosis caused by mutation in the C90RF72 gene on chromosome 9p. Acta Neuropathol. 2012;123(3):409-17. http://dx.doi.org/10.1007/s00401-011-0937-5

34. Cooper-Knock J, Frolov A, Highley JR, et al. C9ORF72 expansions, parkinsonism, and Parkinson disease. A clinicopathologic study. Neurology. 2013;81(9):808-11. http://dx.doi.org/10.1212/ WNL.0b013e3182a2cc38

35. Okamoto K, Mizuno Y, Fujita Y. Bunina bodies in amyotrophic lateral sclerosis. Neuropathology. 2008;28(2):109-15. http://dx.doi.org/ 10.1111/j.1440-1789.2007.00873.x

36. Hudson AJ. Amyotrophic lateral sclerosis and its association with dementia, parkinsonism and other neurological disorders: a review. Brain. 1981;104(2):217-47. http://dx.doi.org/10.1093/brain/104.2.217

37. Boeve BF, Boylan KB, Graff-Radford NR, DeJesus-Hernandez M, Knopman DS, Pdraza $O$ et al. Characterization of frontotemporal dementia and/or amyotrophic lateral sclerosis associated with the GGGGCC repeat expansion in C9ORF72. Brain. 2012;135(3):765-83. http://dx.doi.org/10.1093/brain/aws004

38. Cooper-Knock J, Shaw PJ, Kirby J. The widening spectrum of C90RF72-related disease; genotype/phenotype correlations and potential modifiers of clinical phenotype. Acta Neuropathol. 2014;127(3):333-45. http://dx.doi.org/10.1007/s00401-014-1251-9

39. Beck J, Poulter M., Hensman D, Rohrer JD, Mahoney CJ, Adamson G et al. Large C9orf72 hexanucleotide repeat expansions are seen in multiple neurodegenerative syndromes and are more frequent than expected in the UK population. Am J Hum Genet. 2013;92(3):345-53. http://dx.doi.org/10.1016/j.ajhg.2013.01.011

40. Takada LT, Pimentel ML, DeJesus-Hernandez M, Fong JC, Yokoyama JS, Karydas A et al. Frontotemporal dementia in a Brazilian kindred with the c9orf72 mutation. Arch Neurol. 2012;69(9):1149-53. http:// dx.doi.org/10.1001/archneurol.2012.650

41. Morris HR, Al-Sarraj S, Schwab C, Gwinn_Hardy K, Perez-Tur J, Wood NW et al. A clinical and pathological study of motor neurone disease on Guam. Brain. 2001;124(11):2215-22. http://dx.doi.org/10.1093/ brain/124.11.2215

42. Fong JC, Karydas AM, Goldman JS. Genetic counseling for FTD/ALS caused by the C90RF72 hexanucleotide expansion. Alzheimers Res Ther. 2012;4(4):27. http://dx.doi.org/10.1186/alzrt130

43. Mahoney CJ, Beck J, Rohrer JD, Lashley T, Mok K, Shakespeare T et al. Frontotemporal dementia with the C90RF72 hexanucleotide repeat expansion: clinical, neuroanatomical and neuropathological features. Brain. 2012;135(3):736-50. http://dx.doi.org/10.1093/brain/ awr361

44. Kohli MA, John-Williams K, Rajbhandary R, Naj A, Whitehead P, Hamilton $K$ et al. Repeat expansions in the C9ORF72 gene contribute to Alzheimer disease in Caucasians. Neurobiol Aging. 2013;34(5):1519.e5-12. http://dx.doi.org/10.1016/j.neurobiolaging.2012.10.003

45. Harms M, Benitez BA, Cairns N, Cooper B, Coper P, Mayo K et al. C9orf72 hexanucleotide repeat expansions in clinical Alzheimer disease. JAMA Neurol. 2013;70(6):736-41. http://dx.doi.org/10.1001/ 2013.jamaneurol.537
46. Wojtas A, Heggeli KA, Finch N, Baker M, DeJesus-Hernandez M, Youkin SG et al. C9ORF72 repeat expansions and other FTD gene mutations in a clinical AD patient series from Mayo Clinic. Am J Neurodegener Dis. 2012;1(1):107-18.

47. Simón-Sánchez J, Dopper EG, Cohn-Hokke PE, Hukema RK, Nicolaou $\mathrm{N}$, Seelaar $\mathrm{H}$ et al. The clinical and pathological phenotype of C9ORF72 hexanucleotide repeat expansions. Brain. 2012;135(3):723-35. http://dx.doi.org/10.1093/brain/awr353

48. Blitterswijk M, Baker MC, DeJesus-Hernandez M, Ghidoni R, Benussi L, Finger E et al. C90RF72 repeat expansions in cases with previously identified pathogenic mutations. Neurology. 2013;81(15):1332-41. http://dx.doi.org/10.1212/WNL.0b013e3182a8250c

49. Goldman JS, Quinzii C, Dunning-Broadbent J, Waters C, Mitsumoto H, Brannagan TH 3rd et al. Multiple system atrophy and amyotrophic lateral sclerosis in a family with hexanucleotide repeat expansions in C90RF72. JAMA Neurol. 2014;71(6):771-4. http://dx.doi.org/10.1001/ jamaneurol.2013.5762

50. Fogel BL, Pribadi M, Pi S, Perlman SL, Geschwind DH, Coppola G. C9ORF72 expansion is not a significant cause of sporadic spinocerebellar ataxia. Mov Disord. 2012;27(14):1832-3. http://dx.doi.org/ $10.1002 /$ mds. 25245

51. Lindquist SG, Duno M, Batbayli M, Puschmann A, Braendgaard H, Mardosiene $S$ et al. Corticobasal and ataxia syndromes widen the spectrum of C90RF72 hexanucleotide expansion disease. Clin Genet. 2013;83(3):279-83. http://dx.doi.org/10.1111/j.1399-0004.2012.01903.x

52. Martino D, Stamelou M, Bhatia KP. The differential diagnosis of Huntington's disease-like syndromes: 'red flags' for the clinician. J Neurol Neurosurg Psychiatry. 2013;84(6):650-6. http://dx.doi.org/ 10.1136/jnnp-2012-302532

53. Hensman Moss DJ, Poulter M, Beck J, Hehir J, Polke JM, Campbell T et al. C9orf72 expansions are the most common genetic cause of Huntington disease phenocopies. Neurology. 2014;82(4):292-9. http://dx.doi.org/10.1212/WNL.0000000000000061

54. Meisler MH, Grant AE, Jones JM, Lenk GM, He F, Todd PK et al. C9ORF72 expansion in a family with bipolar disorder. Bipolar Disord. 2013;15(3):326-32. http://dx.doi.org/10.1111/bdi.12063

55. Bieniek KF, Blitterswijk M, Baker MC, Petrucelli L, Rademakers R, Dickson DW. Expanded C9ORF72 hexanucleotide repeat in depressive pseudodementia. JAMA Neurol. 2014;71(6):775-81. http://dx.doi.org/ 10.1001/jamaneurol.2013.6368

56. Snowden JS, Rollinson S, Thompson JC, Harris JM, Stopford CL, Richardson AM et al. Distinct clinical and pathological characteristics of frontotemporal dementia associated with C9ORF72 mutations. Brain. 2012;135(3):693-708. http://dx.doi.org/10.1093/brain/awr355

57. Synofzik M, Biskup S, Leyhe T, Reimold M, Fallgatter AJ, Metzger F. Suicide attempt as the presenting symptom of C9orf72 dementia. Am J Psychiatry. 2012;169(11):1211-3. http://dx.doi.org/10.1176/appi. ajp.2012.12060733

58. Yokoyama JS, Rosen HJ. Neuroimaging features of C9ORF72 expansion. Alzheimers Res Ther. 2012;4(6):45. http://dx.doi.org/ 10.1186/alzrt148

59. Sha SJ, Takada LT, Rankin KP, Yokoyama JS, Tutherford NJ, Fong JC et al. Frontotemporal dementia due to C9ORF72 mutations: clinical and imaging features. Neurology. 2012;79(10):1002-11. http://dx.doi. org/10.1212/WNL.0b013e318268452e

60. Souza PV, Pinto WB, Oliveira AS. Bright tongue sign: a diagnostic marker for amyotrophic lateral sclerosis. Arq Neuropsiquiatr. 2014;72(7):572. http://dx.doi.org/10.1590/0004-282X20140077 